\title{
Readability and Comprehensibility in Translation Using Reading Ease and Grade Indices
}

\author{
Alpaslan Acar (Corresponding author) \\ School of Foreign Languages, Ankara University, Turkey \\ Korkut Uluç İ̧i̇isA $\breve{G}$ \\ Department of Translation and Interpretation, Gazi University, Turkey
}

Received: 19-02-2017

doi:10.7575/aiac.ijclts.v.5n.2p.47
Accepted: 25-04-2017

Published: $30-04-2017$

\begin{abstract}
The study compared and contrasted the readability and comprehensibility levels of technical and scientific texts in English and their Turkish translations through Flesch Reading Ease, Gunning Fog, Flesch-Kincaid Grade Level, The Coleman-Liau Index, The SMOG Index, Automated Readability Index and Linsear Write Formula. Atesman Reading Ease Formula was employed to measure the reading ease of the translated texts in Turkish. To measure the comprehensibility levels of the source texts and target texts, a checklist consisting of source texts and corresponding questions were administered to 43 English lecturers. One text was translated through Google translation. The comprehensibility level ranges from 0 to 100 . (for English text: Comprehensibility level = (total items scores *100)/11; for Turkish texts comprehensibility level $=($ total items scores $* 100) / 12$. If comprehensibility level is $0-20$, comprehensibility is considered very low; 21-40 is low; 41-60 is intermediate; 61-80 is high; $81-100$ is very high. Cronbach's alpha statistics showed the internal consistency is 0,768 for the English texts and 0,796 for the Turkish texts. T-test was used for independent samples. Wilcoxon test was used for two related samples. The results showed that Flesh Reading Formula was compatible to Ateşman Reading Ease Formula. The comprehensibility levels of the source texts and the target texts were found higher than the readability of the texts. The comprehensibility of the target texts was found higher than that of the source texts. A statistical difference was found between the readability and comprehensibility levels of the texts. Google translation had the lowest comprehensibility level.
\end{abstract}

Keywords: Technical Translation, Scientific Translation, Readability, Comprehensibility

\section{Introduction}

Readability and comprehensibility are the thorny and comprehensive issues spanning from the field of education to that of translation studies. In fact, in technical and scientific translation, the translators' main aim is to produce a readable and comprehensible text equivalent to the source text. However, in technical and scientific texts, readability and comprehensibility have often been sacrificed for the sake of conveying the meaning of terminology. Byrne (2006) backs up this conviction implying that the main aim of technical translation is to transmit the technical information to the target audience as efficiently and accurately as possible. In the mists of discussion over terminology and words, the importance of readability and comprehensibility has become the 'Cinderella' of technical and scientific translation. Newmark (1988:151) cautioned us by pointing out that 'terminology accounts for at most just $5-10 \%$ of the total content of technical text', which proves that technical language is more than terminology. Thus, technical translators must also work on producing a readable and comprehensible text in the target language.

The concepts of readability and comprehensibility have been dealt with in several studies. For example, Dubay (2004:3) points out that 'readability is what makes some texts easier to read than others'. Mujiyanto (2016: 1) emphasizes that some factors such as setting, purposes, and psychological as well as sociocultural aspects must be considered in the assessment of readability. Dubay (2004:3) again outlines the principles of readability as follows:

- use short, simple, familiar words

- avoid jargon

- use culture-and-gender-neutral language

- use correct grammar, punctuation, and spelling

- use simple sentences, active voice, and present tense

- begin instructions in the imperative mode by starting sentences with an action verb.

- use simple graphic elements such as bulleted lists and numbered steps to make information visually accessible. 
No doubt, in technical translation, the target translated text must bear those qualities mentioned above as far as the readability is concerned.

However easy the definition of readability may be, the assessment of it has never been so easy and it has always been a subject of interest and controversy among scholars. As understood, the bulk of vocabulary and difficulty of them has become the main benchmark of the readability of a text. Dubay (2004) summarizes in his article that the pursuit to find a tool to measure reading ease goes back to the 1920 s and so far over 200 methods have been developed to assess readability. The Flesch formulas, a tool which is still widely used, The Dale-Chall Formula, The Gunning fog Formula, Fry readability graph, McLaughlin's SMOG Formula, The FORCAST Formula are among the tools employed to gauge the readability of the texts. These tools are mainly based on the average number of syllables per word and the number of words per sentence.

Some recent and illuminating studies have been carried out on the importance of readability. For example, Rezaee \&Norouzi, (2011) have concluded in their study that readability indices and the performance of readers are highly correlated. In addition, Mujiyanto (2016) analyses the comprehensibility and readability of English texts and their backtranslations painstakingly. In his study he reveals the relation between the readability measures and the comprehensibility levels of source texts and their translations, as well as back-renderings. He (2016:26) concludes that texts comprehensibility levels are truly attributed to their readers whereas readability is more text-dependent.'

Comprehensibility and readability are intertwined with each other as they are sometimes used interchangeably; however, they have explicit differences. Comprehension is a reader-oriented approach encompassing the readers' perception, general knowledge, background, cognitive networks of the brain and the like. Kolahi (2012:347) asserts the relationship between readability and comprehensibility by saying that 'readability is a prerequisite for comprehension. Nevertheless, it cannot be concluded that all readable texts are comprehensible or vice versa.

Measuring the comprehensibility of a text has been a focus in several studies, though it is not an easy task. Many researchers have dealt with the concept of comprehensibility. For example, Hönig (1998:49) asserts that readability and comprehensibility are the criteria that determine translation quality assessment. Göpferich (2009) employs six dimensions of comprehension: perceptibility, simplicity, structure, correctness, concision, and motivation. To assess the comprehensibility of a text, he bases his research on functionalist translation theories, especially Scopos theory.

Fallah and Rahimpour (2016) studied the comparison between the readability levels of English scientific texts translated into Persian and found that more readable texts were comprehended better by the students. Schriver (1989) provides a review of these methods and classifies them into three categories: text-focused methods, expert judgment-focused methods, and reader-focused methods. Göpferich (2009:32) regards the reader-focused methods as 'undoubtedly provide the least speculative and most reliable results on text comprehensibility' just because the evaluation of the text is partly based on the comprehension of the reader.

In technical and scientific translation, the readability and comprehensibility of translated texts are highly important. Technical and scientific translations are different from other kinds of translations as they disseminate the scientific knowledge around the world. In this sense, the technical translator's primary task is to make the translation as precise and easy to follow as possible. Technical texts have no intention to impress the readers though connotative and metaphoric ways of expression. The technical texts are simple, unambiguous, concise and to the point. Technical texts are purpose-driven, so their language must be purpose-driven. Casagrande (1954: 335) infers that the goal in technical translation is 'to translate a message efficiently and as accurately as possible'. As inferred from what the researchers said, in an ideal technical and scientific translation comprehensibility, readability and conveying the message as accurately as possible are interconnected. An ideal technical and scientific translation can be illustrated as follows:

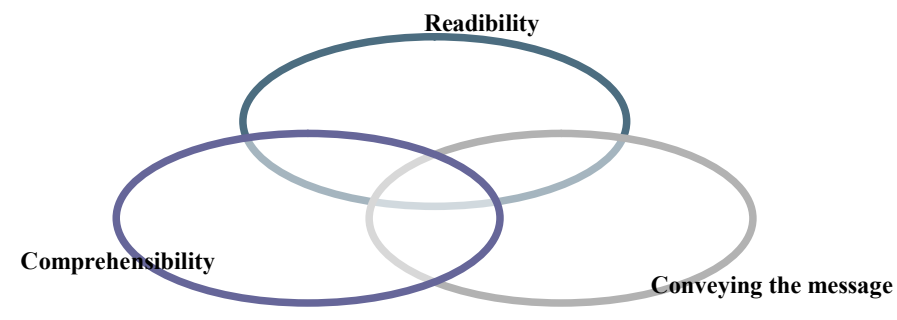

Figure 1. An ideal technical and scientific translation

As seen, these three chains are firmly interconnected and a loose in the chain may lead to a low quality in translation.

However, it is questionable to find these qualities in a scientific and technical translation. Based on the qualities, the following research questions have been sought to answer in the study:

1. Is there a significant difference between the readability of English texts measured through Flesch Reading Ease Formula and the readability ease of Turkish texts measured through Ateşman Reading Ease Formula? 
2. Is there a significant difference between the English texts and their Turkish translations irrespective of text types as far as comprehensibility is concerned?

3. Is there a significant difference between the English texts and their Turkish translations as far as comprehensibility is concerned?

4. How do the Google-based technical and scientific translations differ from human based translation as far as readability and comprehensibility are concerned?

5. Is there a significant difference between the readability and comprehensibility of the source texts?

6. Is there a significant difference between the readability and comprehensibility of the target texts?

7. Is there a significant difference between the comprehensibility of the source and target texts?

\section{Method}

\subsection{Data Collection Instruments}

The data with respect to reading ease was collected through five technical and scientific texts and their five Turkish translations. The data with respect to comprehensibility was collected from 43 academicians teaching English at various universities in Turkey. To evaluate their comprehensibility of the texts, a checklist was developed by the researcher. The checklist for English texts consists of 11 items that question the comprehensibility of the source texts (the items 7 and 8 were reverse coded on SPSS data sheet), whereas the check list for the Turkish translated texts consists of 12 items (the items 7, 8 and 12 were reverse coded on SPSS data sheet). The items were scored from 1 to 0 . The selected items marked by academicians were scored as 1 , whereas the unmarked items were rated as 0 . The comprehensibility level ranges from 0 to 100. (For English text: Comprehensibility level = (total items scores *100)/11 and For Turkish texts comprehensibility level $=($ total items scores $* 100) / 12$. If comprehensibility level is $0-20$, comprehensibility is considered very low; 21-40 is low; 41-60 is intermediate; 61-80 is high; 81-100 is very high. The internal consistency was measured through Cronbach's alpha statistics which measures the internal consistency between the texts. For the English texts, the internal consistency is 0,768 and for the Turkish texts, the internal consistency is 0,796 . Text 1 was taken from a book called 'Using Multivariate Statistic (2001:7), which was translated in 2016 by Baloğlu. Text 3 and its translation (Text 4) were retrieved from the internet site

'https: //umitdural.wordpress.com/ceviri-ornekleri/.' Text 5 was retrieved from the site 'https://www.law.cornell.edu/uscode/pdf/uscode18/lii_usc_TI_18_PA_II_CH_203_SE_3041.pdf. It (Text 6) was translated through Google translation. Text 7 and its translation were retrieved from the site http://www.elektrikport.com/teknik-kutuphane/utopik-bilim-insani-tesla-(elektromanyetik-motor-patenti turkcecevirisi)/8578? fb_comment_id=496392630440345_77647549\#ad-image-0. Text 9 and its Turkish translation, Text 10 were retrieved from the site 'http: //www.turknikon.com/kullanim-kilavuzlari-43'.

\section{Data Analysis}

T-test was used for independent samples. Wilcoxon test was used for two related samples. The source texts' readability was analyzed through Flesch Reading Ease Formula. The source texts' grade levels were analyzed through Gunning Fog, Flesch-Kincaid Grade Level, The Coleman-Liau Index, The SMOG Index, Automated Readability Index, Linsear Write Formula Average Grade Index. To evaluate the reading ease of the translated texts in Turkish, a method developed by Ateşman (1997) was employed. In fact, it is an adaptation of Flesch Reading Ease Formula which complies with the features of the Turkish language.

\section{Findings}

4.1 The findings as to readability ease of English texts measured through Flesch Reading Ease Formula and readability of Turkish texts measured through Ateşman Reading Ease Formula

Table 1. Grade Indices and Reading Ease Scores of the Source Texts

\begin{tabular}{|c|c|c|c|c|c|}
\hline & Text 1 (Eng) & Text 3(Eng) & $\begin{array}{l}\text { Text } 5 \\
\text { (Eng) }\end{array}$ & $\begin{array}{l}\text { Text } \\
\text { (Eng) }\end{array}$ & $\begin{array}{l}\text { Text (9) } \\
\text { Eng) }\end{array}$ \\
\hline Flesch Reading Ease score & 23,5 & -10.6 & 8.4 & 26 & 38.3 \\
\hline Gunning Fog & 19,2 & 25.3 & 34.2 & 17.2 & 19.3 \\
\hline $\begin{array}{l}\text { Flesch-Kincaid Grade } \\
\text { Level }\end{array}$ & 13,8 & 23 & 30.1 & 14.9 & 16.1 \\
\hline The Coleman-Liau Index & 16 & 20 & 8 & 13 & 12 \\
\hline The SMOG Index & 13,1 & 19 & 19.9 & 13.9 & 12.9 \\
\hline $\begin{array}{l}\text { Automated Readability } \\
\text { Index }\end{array}$ & 13,6 & 25.4 & 35.1 & 13.9 & 19.2 \\
\hline Linsear Write Formula & 12,8 & 28.3 & 48.3 & 16.5 & 21.5 \\
\hline Average Grade Index & $\begin{array}{l}14 \\
\text { ( very difficult } \\
\text { to read) }\end{array}$ & $\begin{array}{l}23 \\
\text { (impossible } \\
\text { to read) }\end{array}$ & $\begin{array}{l}28 \\
\text { (very } \\
\text { difficu } \\
\text { lt to } \\
\text { read) }\end{array}$ & $\begin{array}{l}14 \text { ( very } \\
\text { difficult } \\
\text { to read) }\end{array}$ & $\begin{array}{l}16 \\
\text { (difficult } \\
\text { to read) }\end{array}$ \\
\hline
\end{tabular}


The formulas show the reading ease of the source texts and these tools are mainly based on the average number of syllables per word and the number of words per sentence. As seen, the ease levels of technical and scientific texts usually range from difficult to read to impossible to read. It can be concluded that contrary to the notion that technical language is nothing but terminology; in fact, the terminology may make the texts difficult and sometimes impossible to read. Especially Text 2 (medical text) seems too hard to digest as it contains specific terminology and vocabulary. Overall, it can be inferred that in technical and scientific translation, the source texts offer challenges for translators.

Table 2. The comparison of Reading Ease Levels of Source Texts (Eng) and Targets Texts (Turkish)

\begin{tabular}{llllll}
\hline & $\begin{array}{l}\text { Texts } \\
1 / 2\end{array}$ & $\begin{array}{l}\text { Texts } \\
3 / 4\end{array}$ & $\begin{array}{l}\text { Texts } \\
5 / 6\end{array}$ & $\begin{array}{l}\text { Texts } \\
7 / 8\end{array}$ & $\begin{array}{l}\text { Texts } \\
9 / 10\end{array}$ \\
\hline $\begin{array}{l}\text { Flesch Reading Ease } \\
\text { (For the source texts) }\end{array}$ & 23,5 & -10.6 & 8.4 & 26 & 38.3 \\
$\begin{array}{l}\text { Ateşman Reading Ease } \\
\text { Formula ( For the }\end{array}$ & & 39,1 & 16,2 & 18,9 & 13.7 \\
Turkish translated texts) & & & & & \\
\hline
\end{tabular}

Table 3. The comparison of Flesh Scores and Ateşman Scores

\begin{tabular}{lll}
\hline Interpretation of Flesch Scores & Interpretation of Ateşman Scores \\
$100.00-90.00$ & Very easy to read. & $90-100:$ Very easy to read \\
$90.0-80.0$ & Easy to read. & $70-89:$ Easy to read. \\
$80.0-70.0$ & Fairly easy to read. & $50-69:$ Fairly difficult to read \\
$70.0-60.0$ & Easily understood & $30-49:$ Difficult to read. \\
$60.0-50.0$ & Fairly difficult to read. & $1-29:$ Very difficult to read \\
$50.0-30.0$ & Difficult to read. \\
$30.0-0.0$ & Very difficult to read \\
\hline
\end{tabular}

Table 4. The Comparison of Flesh Reading Ease Formula and Atesman Reading Ease Formula (Wilcoxon Test)

\begin{tabular}{|c|c|c|c|c|c|}
\hline & & Mean & $\begin{array}{l}\text { Std. } \\
\text { Deviation }\end{array}$ & Z & $\mathrm{P}$ \\
\hline \multirow[t]{2}{*}{ Pair 1} & $\begin{array}{l}\text { Flesh Reading } \\
\text { Ease Formula }\end{array}$ & 17,12 & 18,792 & \multirow{2}{*}{,$- 405^{b}$} & \multirow{2}{*}{,686 } \\
\hline & $\begin{array}{l}\text { Atesman Reading } \\
\text { Ease Formula }\end{array}$ & 18,26 & 13,044 & & \\
\hline
\end{tabular}

The equivalence between the source and the target texts has always been a controversial issue in technical and scientific translation. Evaluation and assessment of equivalence between the texts have been subjective, depending on the reader's subjective benchmarks. However, technical and scientific translation deserve more than this. In English language, there is more than one formula to assess the ease of texts; however, in Turkish there is only one formula developed by Ateşman. In fact, it is an adaptation of Flesch Reading Ease. In the tables below, the ease of source texts and the translated text were compared.

As seen in the table 2, there is almost full equivalence between the source texts and target texts as far as the reading ease is concerned. It can be inferred from the table that Ateşman Reading Ease formula can be used to measure the ease level of the target texts in Turkish. To compare the results statistically, Wilcoxon test was employed. The test confirms the finding that Flesh Reading Ease Formula and Ateşman Reading Ease Formula are compatible with each other as far as measuring reading ease of the technical and scientific translation.

4.2 The findings as to differences between the English texts and their Turkish translations irrespective of text types as far as comprehensibility is concerned

T-test was used to measure the comprehensibility levels of the English texts and their Turkish translations irrespective of text types for the independent samplings. The comparisons are given in the table 5 .

Table 5. The comparison of all the English texts and their translations in Turkish.

\begin{tabular}{lllllll}
\hline \multicolumn{2}{l}{} & & \multicolumn{5}{l}{ Std. } \\
\multicolumn{1}{l}{ Text Language } & & $\mathrm{N}$ & Mean & $\begin{array}{l}\text { Deviation } \\
\mathrm{t}\end{array}$ & $\mathrm{P}$ \\
\hline Level of & English & 215 & 43,55 & 23,46 & \multirow{2}{*}{, 056} & \multirow{2}{*}{, 955} \\
Comprehensibility & Turkish & 215 & 43,68 & 24,56 & & \\
\hline
\end{tabular}


According to the data collected from the 43 English teachers as to the comprehensibility of the all the texts, the comprehensibility levels of the translated texts are relatively higher than that of the source texts. However, statistically, there is no significant difference between the source texts and the target texts as far as comprehensibility is concerned. $(\mathrm{p}>0.05)$. It can be deduced that the comprehensibility levels of the target texts and the source texts are almost similar.

4.3 The findings as to the difference between the English texts and its Turkish translations as far as comprehensibility is concerned

T-test was used to measure the comprehensibility levels of the English texts and their Turkish translations for the independent samplings. The comparisons are given in the Table 6.

Table 6. The comparison of the Turkish and English texts with respect to comprehensibility

\begin{tabular}{|c|c|c|c|c|c|c|}
\hline Text no & & $\mathrm{N}$ & Mean & $\begin{array}{l}\text { Std. } \\
\text { Deviation }\end{array}$ & $\mathrm{t}$ & $\mathrm{P}$ \\
\hline \multirow[t]{2}{*}{ Text 1} & English & 43 & 54,55 & 21,46 & \multirow{2}{*}{1,906} & \multirow{2}{*}{, 060} \\
\hline & Turkish & 43 & 45,16 & 24,14 & & \\
\hline \multirow[t]{2}{*}{ Text 2} & English & 43 & 45,24 & 22,22 & \multirow{2}{*}{$-1,712$} & \multirow{2}{*}{,091 } \\
\hline & Turkish & 43 & 53,49 & 22,44 & & \\
\hline \multirow[t]{2}{*}{ Text 3} & English & 43 & 38,05 & 23,58 & \multirow{2}{*}{1,219} & \multirow{2}{*}{,226 } \\
\hline & Turkish & 43 & 31,98 & 22,63 & & \\
\hline \multirow[t]{2}{*}{ Text 4} & English & 43 & 39,53 & 22,70 & \multirow{2}{*}{,- 184} & \multirow{2}{*}{,854 } \\
\hline & Turkish & 43 & 40,50 & 26,01 & & \\
\hline \multirow[t]{2}{*}{ Text 5} & English & 43 & 40,38 & 24,40 & \multirow{2}{*}{$-1,347$} & \multirow{2}{*}{, 182} \\
\hline & Turkish & 43 & 47,29 & 23,13 & & \\
\hline
\end{tabular}

The comprehensibility level of Text 1 and Text 3 in the English texts were found higher compared to their comprehensibility levels in Turkish. However, statistically, there is no significant difference between the English texts and their Turkish translations as far as comprehensibility is concerned. $(p>0.05)$. It can be deduced that the comprehensibility levels of the English texts and their translations are almost the same.

4.4 Findings as to the differences between the Google based technical and scientific translation and human based translation with respect to comprehensibility

T-test was used to measure the comprehensibility levels of the English texts and the Turkish texts translated through Google translation for the independent samplings. The comparisons are given in the Table 7.

Table 7. The comparison of comprehensibility levels of the source texts and their comprehensibility levels in the Turkish Texts translated through Google translation.

\begin{tabular}{|c|c|c|c|c|c|c|}
\hline \multicolumn{2}{|c|}{$\begin{array}{l}\text { Comprehensibility } \\
\text { Level }\end{array}$} & \multirow{2}{*}{$\begin{array}{l}\mathrm{N} \\
43\end{array}$} & \multirow{2}{*}{$\begin{array}{l}\text { Mean } \\
31,98\end{array}$} & \multicolumn{2}{|l|}{ Std. } & $\mathrm{p}$ \\
\hline \multirow[t]{2}{*}{ Pair 1} & 6.text & & & 22,63 & \multirow{2}{*}{$-2,611$} & \multirow{2}{*}{, $011 *$} \\
\hline & 2. text & 43 & 45,16 & 24,14 & & \\
\hline \multirow[t]{2}{*}{ Pair 2} & 6.text & 43 & 31,98 & 22,63 & \multirow{2}{*}{$-4,426$} & \multirow{2}{*}{, $000 *$} \\
\hline & 4.text & 43 & 53,49 & 22,44 & & \\
\hline \multirow[t]{2}{*}{ Pair 3} & 6.text & 43 & 31,98 & 22,63 & \multirow{2}{*}{$-1,622$} & \multirow{2}{*}{,109 } \\
\hline & 8.text & 43 & 40,50 & 26,01 & & \\
\hline \multirow[t]{2}{*}{ Pair 4} & 6.text & 43 & 31,98 & 22,63 & \multirow{2}{*}{$-3,103$} & \multirow{2}{*}{, $003 *$} \\
\hline & 10.text & 43 & 47,29 & 23,13 & & \\
\hline
\end{tabular}

*p<0.05

There is a significant difference between the comprehensibility levels of the Texts 2,4 and 10 and the text 6 translated through Google translation $(\mathrm{p}<0.05)$. However, between the Text 8 and the text 6 no significant difference was found $(\mathrm{p}>0.05)$. The text 6 with 31, 98 mean, it has a lower comprehensibility level. Likewise, with 40 mean scores, the text 8 has a lower comprehensibility level. The levels of comprehensibility levels of the texts 2,4 and 10 were found to be intermediate. 
4.5 The findings as to the differences between readability ease and comprehensibility of the source texts

Wilcoxon test was used to find to the differences between readability ease and comprehensibility of the source texts and the comparisons are given in the Table 8.

Table 8 . The comparisons of the comprehensibility and readability levels of the source texts

\begin{tabular}{lllll}
\hline & Mean & $\begin{array}{l}\text { Std. } \\
\text { Deviation }\end{array}$ & $\mathrm{Z}$ & $\mathrm{P}$ \\
\hline $\begin{array}{l}\text { Comprehensibility } \\
\text { level }\end{array}$ & 43,55 & 6,714 & & \\
$\begin{array}{l}\text { Readability Level } \\
{ }^{*} \mathrm{p}<0,05\end{array}$ & 17,12 & 18,792 & $-2,023$ & $0,043^{*}$ \\
\hline
\end{tabular}

A significant difference was found between the comprehensibility and readability levels of the source texts. ( $\mathrm{p}<0.05)$. The mean scores of comprehensibility levels of the source texts are higher than the mean scores of readability levels. However, the readability ease mean scores of the target texts were found to be difficult but their comprehensibility level was found to be less difficult.

4.6 The findings as to the differences between readability ease and comprehensibility of the target texts

Wilcoxon test was used to find to the differences between readability ease and comprehensibility of the target texts and the comparisons are given in the table 9.

Table 9. Comparisons of the comprehensibility and readability levels of the target texts

\begin{tabular}{lllll}
\hline Turkish Texts & Mean & $\begin{array}{l}\text { Std. } \\
\text { Deviation }\end{array}$ & $\mathrm{Z}$ & $\mathrm{P}$ \\
\hline Comprehensibility & 43,68 & 8,038 & $-2,023$ & $0,043^{*}$ \\
Readability & 18,26 & 13,044 & & \\
\hline${ }^{\mathrm{p}}<0.05$ & & &
\end{tabular}

A significant difference was found between the comprehensibility and readability levels of the target texts. $(p<0.05)$. The comprehensibility mean scores of the target texts were found to be higher than the readability mean scores of the target texts. The readability levels of the texts were found to be difficult but their comprehensible level was found to be moderate.

4.7 The findings as to the differences between the comprehensibility of the source and target texts

Wilcoxon test was used to find to the differences between the comprehensibility of English texts and Turkish texts and comparisons are given in the table 10 .

Table 10. The comprehensibility levels of English and Turkish texts

\begin{tabular}{llllll}
\hline & & \multicolumn{3}{l}{$\begin{array}{l}\text { Std. } \\
\text { Deviation }\end{array}$} & Z \\
\hline Pair & English_Comprehensibility & 43,55 & 6,714 & \multirow{2}{*}{, 893} \\
2 & Turkish Comprehensibility & 43,68 & 8,038 &,- 135 & \multirow{2}{*}{, 893} \\
\hline
\end{tabular}

The comprehensibility levels of the source texts were 43, 55 and the rate for the target texts was 43 , 68. It can be concluded that both the source texts and target texts have an intermediate level of comprehensibility. However, no statistical difference was found between the comprehensibility levels of both the source and the target texts. ( $p>0.05)$.

\section{Discussion and Conclusion}

Readability and comprehensibility are two main factors that determine the quality of source texts as well as target texts in technical and scientific translation. In this study, in technical and scientific translation, it has been proven that Ateşman Reading Ease formula, which was formulated to measure the reading ease the Turkish language, turned out to be effective and accurate in measuring the equivalence between the source texts and target texts. The Reading Ease and indices formulas employed in the study showed that both the target texts and the translated texts are over the general reading ease levels. The reading ease results proved that translating technical and scientific translation poses a real challenge to the translators. 
Although there is a close relationship between the readability and comprehensibility, there is not full consistency between them as comprehensibility is related to readers' educational background, perception, culture and etc. The findings showed that comprehensibility levels of the target texts with a mean of 43, 68 are higher than that of the source texts with a mean of 43,55 which proves that translation makes the original more comprehensible compared to the source texts. However, statistically no significant difference between the comprehensibility levels of the English texts and their translations were found.

When the comprehensibility levels of each text was compared to that of target texts, text 1 and text 3 have more comprehensibility levels than their translations. However, this difference is not statistically significant.

Another important result of the study is that a statistically significant difference was found between the comprehensibility levels and readability levels of the source texts though the source texts were found to be more comprehensible compared to their reading ease scores.

The Wilcoxon test showed that comprehensibility levels of source texts are higher than reading ease of the texts. ( $p<0$, 05).

Likewise, a significant difference was found between the comprehensibility and readability of the target texts, which shows that there is a close relationship between comprehensibility and readability in translated texts. The results again disclosed the comprehensibility levels of the translated texts are higher than their reading ease levels.

When comprehensibility of levels of the target texts with a 43,68 mean and source texts with a 43,58 mean were compared statistically, their overall mean scores were almost the same, which proves that checklist developed to measure the compressibility levels of the target texts are accurate, reliable and valid. It also shows that the comprehensibility levels of the source and target texts are similar.

Another striking conclusion is that Google translation has improved its translation quality and accuracy; yet, it is still inefficient in producing quality translation compared to human translation. Technical and scientific translation which have no margin of mistake are too important to leave at the mercy of machine translation such as Google translation. With 31, 98 comprehensibility level, comprehensibility level of the target text translated through Google translation has the lowest comprehensibility level.

\section{References}

Ateşman, E. (1997). Türkçe'de okunabilirliğin ölçülmesi. A. ̈. Tömer Dil Dergisi. 58,171-174.

Casagrande, J. B. (1954). The Ends Of Translation. International Journal of American Linguistics, (20) (4).

Çeviri Örnekleri (N.D). Retrieved March 17 from https://umitdural.wordpress.com/ceviri-ornekleri/

Crimes and Criminal Procedure (2012). Retrieved March 17 from

https://Www.Law.Cornell.Edu/Uscode/Pdf/Uscode18/Lii_Usc_TI_18_PA_II_CH_203_SE_3041.Pdf
DuBay, W. (2008). The Principles Of Readability. Costa Mesa: Impact Information, (949), 77. https://doi.org/10.1.1.91.4042

Fallah, S. (2016). Cohesive Devices In Translation: A Comparison Between The Readability Levels Of English Scientific Texts Translated Into Persian. Internatıonal Journal of Humanities and Cultural Studies. March Special Issue, 1299-1315.

Göpferich, S. (2009). Comprehensibility Assessment Using The Karlsruhe Comprehensibility Concept. The Journal of Specialised Translation, (11), 12-38. Retrieved from http://www.jostrans.org/issue11/art_goepferich.pdf

Hönig, H. G. (1998). Positions, Power And Practice: Functionalist Approaches And Translation Quality Assessment. christina schäffner (Ed.) (1998). Translation and Quality. Clevedon etc.: Multilingual Matters, 6-34.

Jody, B. (2006). Technical Translation Usability Strategies For Translating Technical Documantation. dordrech: Springer.

Kolahi, S., \& Shirvani, E. (2012). A Comparative Study Of The Readability Of English Textbooks Of Translation And Their Persian Translations. International Journal of Linguistics, 4(4), 344-361. https://doi.org/10.5296/ij1.v4i4.2737

Mujiyanto, Y. (2016). The Comprehensibility Of Readable English Texts And Their Back-Translations. International Journal of English Linguistics, 6(2), 21. https://doi.org/10.5539/ijel.v6n2p21

Newmark, P. (1988). A textbook of translation. New York and London: Prentice Hall.

Rezaee, A. A., \& Norouzi, M. H. (2011). Readability Formulas And Cohesive Markers In Reading Comprehension. Theory and Practice in Language Studies, 1(8), 1005-1010. https://doi.org/10.4304/tpls.1.8.1005-1010

Robinson, D. (2003). Becoming a Translator (Second Ed). London \& New York: Rutledge.

Schriver, K. A. (1989). Evaluating text quality: the Continuum from Text-focused to Reader-focused Methods. IEEE

Transactions on Professional Communication, 32(4), 238-255. https://doi.org/10.1109/47.44536

Tabachnick, B. G., \& Fidel, L. S. (2001). Using Multivariate Statistics (4th ed.). Boston, Mass.: Allyn and Bacon.

Tabachnick, B. G.; Fidell, L. S., (2015). Çok değişkenli istatistiklerin kullanımı (Baloğlu, M., Çev.). Ankara: Nobel Yayın Dağıtım

Ütopik Bilim İnsanı TESLA (N.D). Retrived March 17 from http://www.elektrikport.com/teknik-kutuphane/utopikbilim-insani-tesla-(elektromanyetik-motor-patenti-turkcecevirisi) $/ 8578$ fb_comment_id $=496392630440345$

77647549\#ad-image-0 